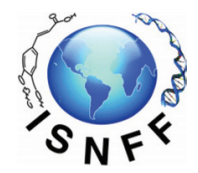

\title{
Wood extracts as unique sources of soluble and insoluble-bound phenolics: reducing power, metal chelation and inhibition of oxidation of human LDL-cholesterol and DNA strand scission
}

\author{
Tasahil Albishia ${ }^{\mathrm{a}, \mathrm{c}}$, Joseph H. Banoub ${ }^{\mathrm{a}, \mathrm{b}}$, Adriano Costa de Camargo ${ }^{\mathrm{a}}$ and \\ Fereidoon Shahidi ${ }^{*}$
}

\begin{abstract}
aDepartment of Biochemistry, Memorial University of Newfoundland, St. John's, NL, Canada A1B 3X9

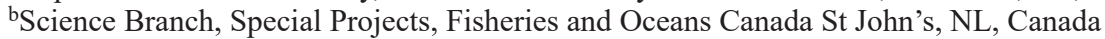

${ }^{\mathrm{c}}$ Current address: Department of Biology, Applied Science College, Umm Al-Qura University, Mecca, Saudi Arabia.

*Corresponding author: Fereidoon Shahidi, Department of Biochemistry, Memorial University of Newfoundland, St. John's, NL, Canada A1B 3X9. Tel: +1 (709) 864-8552; Fax: +1 (709) 864-2422; E-mail: fshahidi@mun.ca

DOI: $10.31665 /$ JFB.2019.8211

Received: December 25, 2019; Revised received \& accepted: December 30, 2019

Citation: Albishi, T., Banoub, J.H., de Camargo, A.C, and Shahidi, F. (2019). Wood extracts as unique sources of soluble and insolublebound phenolics: reducing power, metal chelation and inhibition of oxidation of human LDL-cholesterol and DNA strand scission. J. Food Bioact. 8: 92-98.
\end{abstract}

\begin{abstract}
Palm date is an important crop in many Middle Eastern countries. In the present study, seedling date palm wood and old date palm wood were evaluated for their phenolics content. It was found that they may serve as rich sources of soluble and insoluble-bound phenolics with promising reducing power and metal chelation. The observed effects were compared with those of oak, quibracho, banana, and pine woods. Syringic acid, (+)-catechin, and (+)-gallocatechin were present in five out of the six tested samples, as evaluated by MALDI-TOF-MS. Therefore, these compounds are good candidates to be monitored by the industry in order to define quality parameters. Additionally, due to their strong ability to counteract DNA damage caused by peroxyl and hydroxyl radicals (up to $98.42 \%$ ) and cupric ion-induced human low-density lipoprotein-cholesterol (LDL-C) peroxidation in vitro (up to $95.80 \%$ ), wood phenolics may render antimutagenic effects and protection against cardiovascular diseases.
\end{abstract}

Keywords: Wood by-products; Total phenolic content; MALDI-TOF-MS; Peroxyl radical; Hydroxyl radical; DNA oxidation inhibition; Low-density lipoprotein oxidation control.

1. Introduction

The potential use of naturally occurring plant bioactives has attracted much interest mainly because they are environmentally friendly and may provide better safety for consumers in comparison to their synthetic counterparts. The potential bioactives of plant industrial by-products may also be interesting from an economic standpoint (de Camargo et al., 2018; Louli et al., 2004; Moure et al., 2001; Shahidi et al., 2019) as many of them are discarded. Several studies have focused on food by-products as sources of phenolic bioactives. In contrast, by-products generated during wood processing have received little attention, despite their great potential as sources of bioactive compounds for possible use in the manufacture of nutraceuticals and natural health products (Domenek et al., 2013).

Phenolic acids, flavonoids (including anthocyanins and proanthocyanins), lignans, and lignins are well-characterized natural antioxidants (Albishi et al., 2019b; de Camargo et al., 2015; Valdez et al., 2019). The variety of polyphenols is large, and the diversity is further affected and possibly increased due to changes occurring during the course of sample preparation (e.g. oven-drying, spray-drying; and freeze-drying), extraction (e.g. solvent-assisted extraction, enzyme-assisted extraction, ultrasound-assisted extraction), as well as up-scaling (Crestini et al., 2011; de Camargo et al., 2016; de Camargo et al., 2018).

Regardless of the method used for the recovery of phenolic compounds, most reports ignore the fraction remaining after the extrac- 
tion of soluble phenolics. As evidence on the major contribution of phenolics present in the insoluble-bound form is better recognized, screening the phenolic profiles in the insoluble-bound fraction and their potential bioactivity becomes mandatory. Insoluble-bound phenolics are linked to the cell wall of the plant components and must be hydrolyzed so that the real concentration of polyphenols in the starting material could be evaluated (Shahidi and Yeo, 2016). In addition, several studies have addressed the phenolic profile and potential health benefits of single samples, thus ignoring the importance of comparative studies. Therefore, the aim of the present study was to recover soluble phenolics from selected woods as well as those released from their insoluble-bound counterparts. The antioxidant potential of samples was screened by chemicalbased methods, and their potential bioactivity was determined using models related to potential cancer and cardiovascular disease initiation.

\section{Materials and methods}

\subsection{Materials}

The woods used in the present investigation included seedling date palm wood (SPW), old date palm wood (OPW), oak wood $(\mathrm{OW})$, quibracho $(\mathrm{QW})$, pinewood $(\mathrm{PW})$, and banana $(\mathrm{BW})$. The heartwood from OPW was 28 years old, SPW tree 4 years old. OPW and SPW woods were collected manually from the Salman Alfarsi Garden, Almadinah, Saudi Arabia, and the OW, PW, QW, and BW samples, were collected from the French Company Industrial de la Matiere Vegetale (CIMV). All samples were freezedried for 7 days at $-48^{\circ} \mathrm{C}$ and $30 \times 10^{-3} \mathrm{mbar}$ (Freezone 6, model 77530, Labconco Co., Kansas City, MO, USA). The dried samples were then ground, vacuum packed and stored in a freezer at $-20{ }^{\circ} \mathrm{C}$ until used for analysis within 5 days. All experiments were carried out in triplicates, and the results were reported as mean \pm standard deviation. The methodologies followed are described below. Organic solvents were purchased from Fisher Scientific Co. (Nepean, ON, Canada). The remaining chemicals and reagents were obtained from Sigma-Aldrich Canada Ltd. (Oakville, ON, Canada).

\subsection{Extraction of phenolics}

The fractions containing soluble and insoluble-bound phenolics were obtained as described elsewhere (Albishi et al., 2019a). Freeze-dried woods $(5 \mathrm{~g})$ were ultrasonicated for $20 \mathrm{~min}$ at 30 ${ }^{\circ} \mathrm{C}$ with $150 \mathrm{~mL}$ of a mixture of methanol-acetone-water $(7: 7: 6$, $\mathrm{v} / \mathrm{v} / \mathrm{v})$. The resulting slurries were centrifuged at $4,000 \times g($ ICE Centra MS, International Equipment Co., Needham Heights, MA, USA) for $5 \mathrm{~min}$ and the supernatants collected. The residue was re-extracted under the same conditions. After centrifugation, the combined extracts were analyzed for soluble phenolics, and the residue was reserved for determination of insoluble-bound phenolics. The combined supernatants were evaporated under vacuum at $40{ }^{\circ} \mathrm{C}$ to remove the organic solvents, and the aqueous phase was adjusted to $\mathrm{pH} 2$ before extraction with hexane to remove interfering lipids (Sosulski et al., 1982). The solid residues remaining after the extraction of soluble phenolics were dispersed in $50 \mathrm{~mL}$ of $4 \mathrm{M}$ $\mathrm{NaOH}$ and stirred for 4 hours under nitrogen. The alkaline solution was acidified to $\mathrm{pH} 2$ using $6 \mathrm{M} \mathrm{HCl}$ and the bound phenolics were recovered with diethyl ether-ethyl acetate $(1: 1, \mathrm{v} / \mathrm{v})$. The organic solvent was evaporated and HPLC grade methanol was used to resuspend the phenolic extracts.

\subsection{Determination of total phenolic content}

The total phenolic content was determined according to an improved version of the procedure explained by Singleton and Rossi (1965) with minor changes as previously described (Albishi et al., 2013b). Total extracted phenolics were expressed as mg of gallic acid equivalents per gram of wood extract.

\subsection{Identification of phenolic compounds by MALDI-TOF-MS}

The MALDI-TOF-MS spectra were recorded on a Bruker Reflex III instrument (Bremen, Germany). The irradiation source was a pulsed nitrogen laser with a wavelength of $337 \mathrm{~nm}$, and the duration of the laser pulse was $3 \mathrm{~ns}$. In the negative reflection mode, an accelerating voltage of $20.0 \mathrm{kV}$ and a reflection voltage of $23.0 \mathrm{kV}$ were used. The spectra of phenolics were obtained from a sum of 100-150 shots. The compound 2,5-dihydroxybenzoic acid (DHB, $1 \mathrm{mg} / \mathrm{mL})$ was used as the matrix. The sample solutions $(1 \mathrm{mg} /$ $\mathrm{mL}$ ) were mixed with the matrix solution at a volumetric ratio of 1:3. The mixture $(1 \mu \mathrm{L})$ was applied to the steel target. Amberlite IRP-64 cation-exchange resin, equilibrated in deionized water, was used to deionize the analyte/matrix solution three times.

\subsection{Reducing power}

The reducing power of wood extracts was determined according to Albishi et al. (2013b). Briefly, each extract $(0.2-1.0 \mathrm{mg})$ was dissolved in $1.0 \mathrm{~mL}$ of distilled water to which $2.5 \mathrm{~mL}$ of a $0.2 \mathrm{M}$ phosphate buffer $(\mathrm{pH} 6.6)$ and $2.5 \mathrm{~mL}$ of a $1 \%(\mathrm{w} / \mathrm{v})$ solution of potassium ferricyanide were added for determination of reducing power. The mixture was incubated in a water bath at $50{ }^{\circ} \mathrm{C}$ for 20 min. Subsequently, $2.5 \mathrm{~mL}$ of a $10 \%(\mathrm{w} / \mathrm{v})$ solution of trichloroacetic acid were added, and the mixture was then centrifuged at $1,750 \times g$ for $10 \mathrm{~min}$. Subsequently, a $2.5-\mathrm{mL}$ of the supernatant was combined with $2.5 \mathrm{~mL}$ of distilled water and $0.5 \mathrm{~mL}$ of a $0.1 \%$ $(\mathrm{w} / \mathrm{v})$ solution of ferric chloride. The absorbance of the reaction mixture was read spectrophotometrically at $700 \mathrm{~nm}$; the increased absorbance of the reaction mixture indicates greater reducing power. Results were expressed as $\mu$ moles trolox equivalents.

\subsection{Measurement of iron (II) chelation capacity}

The chelation of ferrous ions by the extract was estimated by the method of Liyana-Pathirana and Shahidi (2006), with some modifications. In brief, $0.5 \mathrm{~mL}$ of extract was mixed with $1.85 \mathrm{~mL}$ of methanol and $0.05 \mathrm{~mL}$ of $1 \mathrm{mmol} / \mathrm{L}$ ferrozine, followed by vigorous shaking and allowing the mixture to react at room temperature for $10 \mathrm{~min}$. The absorbance was read spectrophotometrically at $562 \mathrm{~nm}$. The chelation capacities were expressed as $\mu$ mol ethylenediaminetetraacetic acid (EDTA) equivalents/g of wood extract.

\subsection{Supercoiled DNA strand scission induced by peroxyl and hy- droxyl radicals}

The inhibition activity phenolic wood extracts against supercoiled DNA strand scission induced by peroxyl and hydroxyl radicals was evaluated according to the method described by Albishi et 
al. (2013a). The protective effect of wood extracts was calculated based on the following equation:

DNA retention $(\%)=100$ (supercoiled DNA content in sample/ supercoiled DNA in the control)

\subsection{Inhibition of cupric ion-induced human low-density lipopro- tein-cholesterol (LDL-c) peroxidation}

The inhibitory effect of wood extracts on cupric ion-induced human LDL-c peroxidation was determined according to Albishi et al. (2013a). Tannic acid, syringic acid, gallic acid, and catechin (100 ppm) were used as positive controls. The appropriate blanks were run for each sample by replacing LDL-c and $\mathrm{CuSO} 4$ with distilled water for background correction. All results were expressed as inhibition percentage (de Camargo et al. 2015).

\subsection{Statistical analysis}

All experiments were carried out in triplicates, and results were reported as mean \pm deviation. The significance of differences among the values was determined at $\mathrm{p}<0.05$ using analysis of variance (ANOVA) followed by Tukey's multiple range tests.

\section{Results and discussion}

\subsection{Total phenolics and MALDI-TOF-MS analysis}

The total soluble and insoluble-bound phenolics were determined in wood samples. The content of soluble phenolics in each tested wood decreased in the order of seedling date palm wood (SPW) $>$ old date palm wood $(\mathrm{OPW})>$ oak wood $(\mathrm{OW})>$ quibracho wood $(\mathrm{QW})>$ pinewood $(\mathrm{PW})>$ banana wood $(\mathrm{BW})$. Extracts from BW had the lowest amount of soluble and bound phenolics, compared to other wood varieties (Table 1). Furthermore, the fraction containing soluble phenolics made the highest contribution to the total content recovered (soluble plus insoluble-bound phenolics).
Table 1. Total phenolic contents (TPC) of woods extracts (mg GAE/g of $\mathrm{WE})^{*}$

\begin{tabular}{lll}
\hline \multirow{2}{*}{ Feedstock } & \multicolumn{2}{c}{ Fraction } \\
\cline { 2 - 3 } & soluble & insoluble-bound \\
\hline OPW & $74.65 \pm 2.62^{\mathrm{b}}$ & $19.67 \pm 0.87^{\mathrm{a}}$ \\
SPW & $80.03 \pm 4.47^{\mathrm{a}}$ & $21.05 \pm 0.60^{\mathrm{a}}$ \\
OW & $59.45 \pm 4.82^{\mathrm{c}}$ & $10.80 \pm 0.10^{\mathrm{b}}$ \\
PW & $24.76 \pm 0.26^{\mathrm{d}}$ & $7.54 \pm 0.33^{\mathrm{d}}$ \\
QW & $43.34 \pm 0.72^{\mathrm{c}}$ & $12.41 \pm 0.14^{\mathrm{b}}$ \\
BW & $19.76 \pm 1.01^{\mathrm{d}}$ & $5.98 \pm 0.01^{\mathrm{c}}$ \\
\hline
\end{tabular}

*GAE, gallic acid equivalents; WE, wood extract; OPW, old date palm wood; SPW seedling date palm wood; OW, oak wood; PW, pinewood; QW, quibracho wood; BW, banana wood. Data represent mean values \pm standard deviation $(n=3)$. Values followed by the same letters within a column are not significantly different $(p>0.05)$.

Except for date palm wood, which has been employed in preparation of smoked salmon (Albishi et al., 2019a), the present investigation is the first study that evaluates the contribution of bound phenolics in several types of wood. Therefore, due to different extraction procedures, comparison with the literature data is not possible. However, considering the soluble fraction, the TPC of SPW is quite similar to that of Myrocarpus fastigiatus wood (Dudonné et al., 2009).

Identification of the major phenolic compounds in samples was carried out to better explain the potential bioactivity of wood extracts (Table 2). SPW, which exhibited the highest TPC, showed the presence of protocatechuic acid, coniferylaldehyde, homovanillic acid, syringic acid, sinapaldehyde, $(+)$-catechin, and $p$-coumaric acid 4-O-glucoside. In contrast, catechol, syringic acid, 3'-hydroxydihydrodaidzein, kaempferol, (+)-catechin, (+)-gallocatechin, and rhamnetin were detected in BW, which showed the lowest TPC. Syringic acid, (+)-catechin, and (+)-gallocatechin were present in 5 out of 6 samples tested. Therefore, these compounds are good candidates to be monitored by the user industry in order to define the best parameters for quality control purposes.

Syringic acid that was identified in this work is also found

Table 2. Phenolic compounds identified in woods by MALDI-TOF-MS

\begin{tabular}{|c|c|c|c|c|c|c|c|}
\hline MW & Identification & OPW & SPW & OW & PW & QW & BW \\
\hline 110 & catechol & & & + & + & + & + \\
\hline 154 & protocatechuic acid & + & + & & + & + & \\
\hline 178 & coniferylaldehyde & + & + & & & + & \\
\hline 182 & homovanillic acid & + & + & & + & + & \\
\hline 196 & hydroxycaffeic acid & & & + & & + & \\
\hline 198 & syringic acid & + & + & & + & + & + \\
\hline 208 & sinapaldehyde & + & + & & & & \\
\hline 272 & 3'-hydroxydihydrodaidzein & & & + & + & + & + \\
\hline 286 & kaempferol & & & + & + & + & + \\
\hline 290 & $(+)$-catechin & + & + & + & + & & + \\
\hline 306 & $(+)$-gallocatechin & + & & + & + & + & + \\
\hline 316 & rhamnetin & & & & + & + & + \\
\hline 326 & $p$-coumaric acid 4-O-glucoside & + & + & & + & + & \\
\hline
\end{tabular}

OPW, old date palm wood; SPW, seedling date palm wood; OW, oak wood; PW, pinewood; QW, quibracho wood; BW, banana wood. 
Table 3. Reducing power (RP) and iron (II) chelation capacity (CC) of wood extracts

\begin{tabular}{|c|c|c|c|c|}
\hline \multirow{2}{*}{ Feedstock } & \multicolumn{2}{|c|}{ RP (mmoles TE/g WE) } & \multicolumn{2}{|c|}{ CC ( $\mu$ moles EE/g WE) } \\
\hline & Soluble & Insoluble-bound & Soluble & Insoluble-bound \\
\hline OPW & $1.18 \pm 0.32^{\mathrm{a}}$ & $0.13 \pm 0.004^{d}$ & $10.82 \pm 1.60^{b}$ & $11.42 \pm 1.67^{\mathrm{b}}$ \\
\hline SPW & $1.37 \pm 0.02^{\mathrm{a}}$ & $0.81 \pm 0.03^{a}$ & $21.17 \pm 1.44^{a}$ & $12.95 \pm 1.85^{\mathrm{a}}$ \\
\hline OW & $0.55 \pm 0.04^{b}$ & $0.30 \pm 0.008^{c}$ & $10.68 \pm 1.33^{b}$ & $10.28 \pm 2.44^{c}$ \\
\hline PW & $0.59 \pm 0.14^{b}$ & $0.70 \pm 0.05^{b}$ & $6.94 \pm 1.65^{c}$ & $3.08 \pm 4.46^{d}$ \\
\hline QW & $1.15 \pm 0.27^{a}$ & $0.68 \pm 0.007^{b}$ & $9.86 \pm 1.55^{b}$ & $8.59 \pm 7.48^{c}$ \\
\hline BW & $0.35 \pm 0.03^{c}$ & $0.10 \pm 0.004^{d}$ & $5.54 \pm 1.25^{c}$ & $2.28 \pm 2.48^{d}$ \\
\hline
\end{tabular}

TE, trolox equivalent; EE, EDTA equivalents; OPW, old date palm wood; SPW, seedling date palm wood; OW, oak wood; PW, pinewood; QW, quibracho wood; BW, banana wood. Data represent mean values \pm standard deviation $(n=3)$. Values followed by the same letters within a column are not significantly different $(p>0.05)$.

in nuts, fruits, culinary herbs, and their processing by-products (Alvarez-Parrilla et al., 2018; Mirfat et al., 2018; Senanayake, 2018; Shahidi and Hossain, 2018). In contrast, while several feedstocks show catechin in their phenolic profile (Amarowicz and Shahidi, 2018; Silva et al., 2018; Silva et al., 2019), the presence of gallocatechin is not as common.

Green tea is a classic example of a source of galloylated catechins (Li et al., 2019). Furthermore, the presence of catechin, but not gallocatechin, has also been reported in date seed (John and Shahidi, 2019). The literature supports the anti-inflammatory potential of phenolic compounds from several feedstocks (de Camargo et al., 2019; Falcão et al., 2019; John and Shahidi, 2019) and, in general, a higher antioxidant activity translates in higher anti-inflammatory potential. Therefore, due to the probable positive effect on inflammatory responses taking place in chronic ailments such as cancer, cardiovascular diseases, type 2 diabetes and obesity, and the parameters investigated in the present study, byproducts generated during wood processing may be considered as rich sources of multifunctional natural compounds for the nutraceutical industry.

\subsection{Reducing power, and iron (II) chelation capacity}

A recent study (de Camargo et al., 2019) showed that ferric reducing antioxidant power (FRAP) assay may anticipate the biological activity of phenolic extracts in cell models. However, ferrous ions generated in this reaction may also induce lipid oxidation. Therefore, besides being a good reducing agent, an "ideal antioxidant" may also exhibit chelating capacity resulting from its specific structural features. Accordingly, the chelating ability of the phenolics were investigated in the present study (Table 3 ).

The reducing power of the fraction containing soluble phenolics ranged from 0.35 to $1.18 \mathrm{mmol}$ trolox equivalents/g of wood extract while the metal chelation values ranged from 5.54 to 21.17 $\mu$ mol EDTA equivalents/g of wood extract. All fractions containing phenolics released from their insoluble-bound form also showed reducing power and chelation capacity. The reducing power $(\mathrm{r}=$ $0.744)$ and the metal chelation capacity $(\mathrm{r}=0.699)$ showed significant $(p<0.05)$ positive correlations with TPC (Table 1$)$.

\subsection{Evaluation of antioxidant activity of wood extracts in bio- logical model systems}

The fraction containing soluble phenolics made the highest contribution to the total phenolic content (soluble plus insoluble-bound) and, hence, was tested in two biological in vitro model systems, namely ROS-induced supercoiled strand DNA scission and cupric ion-induced human low-density lipoprotein cholesterol (LDL-c) peroxidation.

3.3.1. Supercoiled strand DNA scission induced by peroxyl and hydroxyl radicals

The inhibitory activity of phenolic extracts $(20 \mu \mathrm{g} / \mathrm{mL})$ towards peroxyl and hydroxyl radical-induced DNA damage is shown in Table 4 . In addition, Figures 1 and 2 show, respectively, the activity of soluble wood extracts in inhibiting peroxyl and hydroxyl radical-induced DNA supercoiled strand scission.

Hydroxyl radicals were generated by Fenton reaction in the presence of $\mathrm{H}_{2} \mathrm{O}_{2}$ and $\mathrm{FeSO}_{4}$. The chelation capacity of phenolics from wood extract was mentioned before (Table 3). Therefore, the scavenging of hydroxyl radicals along with metal chelation may be the possible operative mechanisms explaining the protection of DNA towards hydroxyl radical induced-damage.

SPW and OPW exhibited the highest protection towards DNA damage induced by hydroxyl radical (98.42 and $86.49 \%$, respectively) which was followed by OW $(69.41 \%)$, QW $(89.06 \%)$, and BW (77.89\%), which showed statistically similar activities, whereas PW (51.85\%) had the lowest activity. Likewise, soluble phenolics from SPW were most efficient in protecting DNA from peroxyl radical-induced damage, while those extracted from PW showed the lowest activity. Their efficiencies were 36.54 and

Table 4. Inhibition of DNA strand scission (\%) of soluble wood phenolics towards hydroxyl- and peroxyl-induced oxidation*

\begin{tabular}{lll}
\hline \multirow{2}{*}{ Feedstock } & \multicolumn{2}{c}{ DNA strand scission inhibition (\%) } \\
\cline { 2 - 3 } & Hydroxyl radical & Peroxyl radical \\
\hline SPW & $36.54 \pm 2.39 a$ & $98.42 \pm 0.91 \mathrm{a}$ \\
OPW & $38.64 \pm 0.74 \mathrm{a}$ & $86.39 \pm 1.94 \mathrm{~b}$ \\
OW & $29.85 \pm 1.93 \mathrm{~b}$ & $69.41 \pm 1.97 \mathrm{c}$ \\
PW & $19.05 \pm 0.63 \mathrm{c}$ & $51.85 \pm 2.66 \mathrm{c}$ \\
QW & $27.07 \pm 3.69 \mathrm{~b}$ & $89.06 \pm 0.89 \mathrm{~b}$ \\
BW & $24.88 \pm 4.66 \mathrm{~b}$ & $77.89 \pm 2.13 \mathrm{c}$
\end{tabular}

OPW, old date palm wood; SPW, seedling date palm wood; OW, oak wood; PW, pinewood; QW, quibracho wood; BW, banana wood. Data represent mean values \pm stand ard deviation $(n=3)$. Values followed by the same letters within a column are not significantly different $(p>0.05)$ 


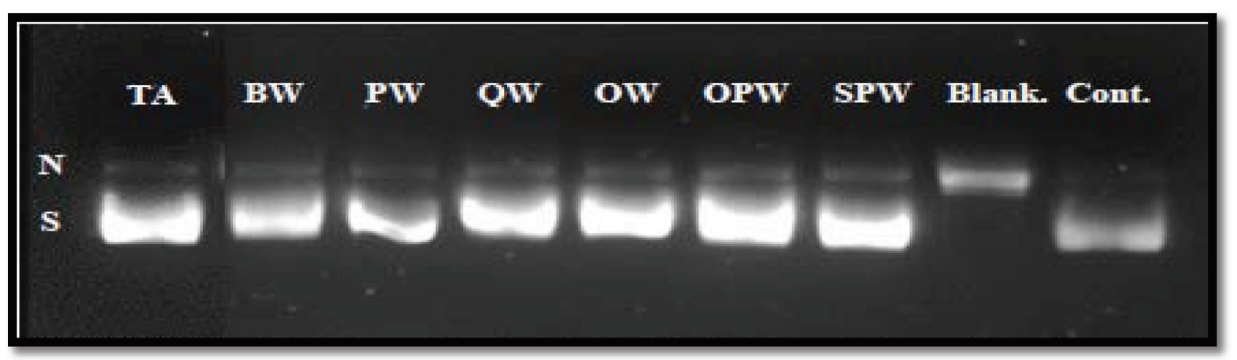

Figure 1. Agarose gel electrophoresis of inhibition of peroxyl radical-induced DNA scission by soluble wood extracts. N (nicked), S (supercoiled) DNA. TA, tannic acid; BW, banana wood; PW, pinewood; QW, quibracho wood; OW, oak wood; OPW, old date palm wood; SPW, seedling date palm wood.

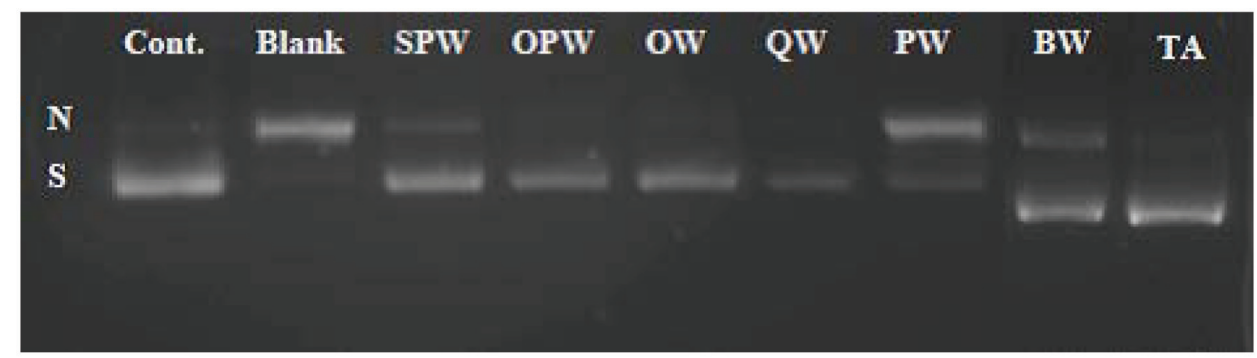

Figure 2. Agarose gel electrophoresis of inhibition of hydroxyl radical-induced DNA scission by soluble wood extracts. N (nicked), S (supercoiled) DNA. ; SPW, seedling date palm wood; OPW, old date palm wood; OW, oak wood; PW, pinewood; QW, quibracho wood; BW, banana ; TA, tannic acid.

$19.05 \%$, respectively. Tannic acid, used as a positive control (Figure 1), showed $87.93 \%$ inhibition of DNA damage against peroxyl radical, and this was lower than that of SPW but similar to those of QW and OPW.

Regardless of the sample, phenolics from wood extract were more effective against peroxyl radical. A few studies have shown hydroxyl radical scavenging activity of wood. Sathya and Siddhuraju (2012) showed that the phenolics extracted from the bark of empty pod exhibited a protective effect against hemolysis of human red blood cells induced by AAPH as a source of peroxyl radicals, and this was comparable to the protective effect of BHA and tannic acid. Therefore, considering the literature (Sathya and Siddhuraju, 2012) and our results, it is possible to suggest that phenolics from wood may be used in order to protect the DNA from oxidized damage and possibly in supplements that may act as antimutagenic agents in cancer prevention and/or treatment.

3.3.2. Inhibition of cupric ion-induced human low-density lipoprotein (LDL) peroxidation

The protective effect of soluble phenolics was tested towards

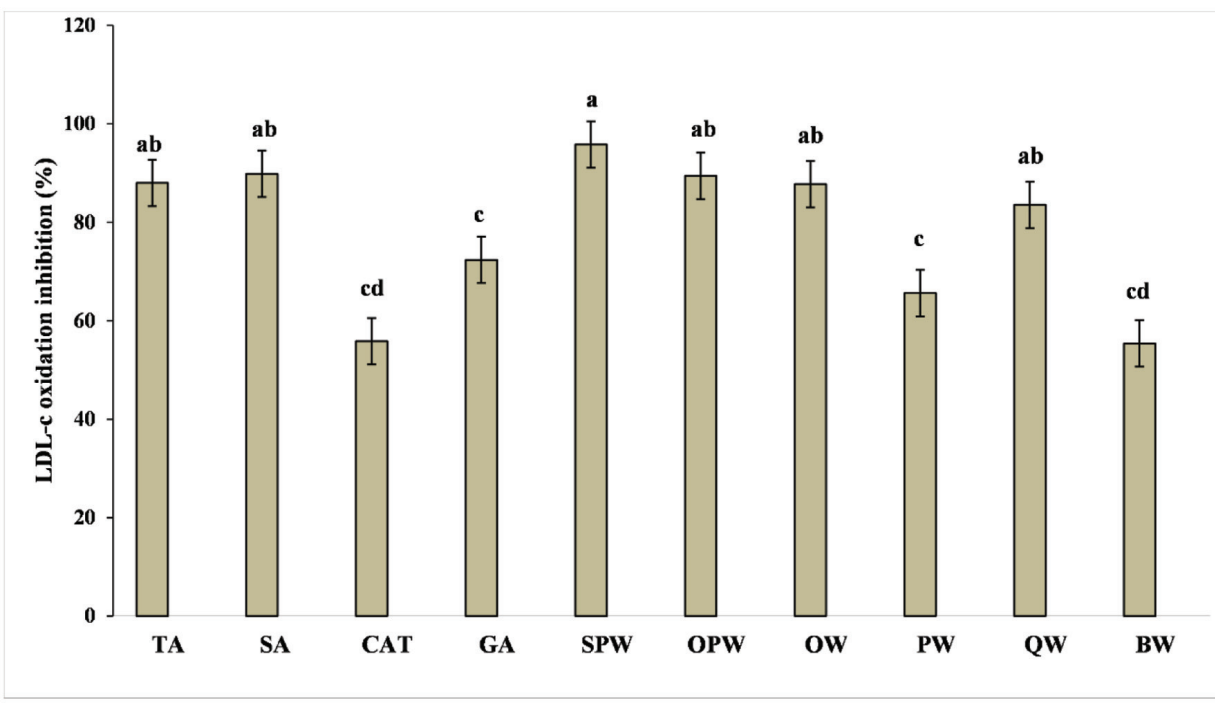

Figure 3. Inhibition of cupric ion-induced human low-density lipoprotein (LDL) peroxidation. TA, tannic acid; SA, syringic acid; CAT, catechin; GA, gallic acid; SPW, seedling date palm wood; OPW, Saudi old date palm wood; OW, oak wood; PW, pinewood; QW, quibracho wood; BW, banana wood. 
cupric ion-induced human low-density lipoprotein cholesterol (LDL-c) peroxidation in vitro (Figure 3 ). Soluble phenolic extracts obtained from BW exhibited the lowest inhibitory effect against LDL-c oxidation, which was comparable to that of PW. According to the literature (Ambigaipalan et al., 2016), low inhibitory effects may be explained by the poor chelating ability of phenolics present in the test sample. In fact, in this study, no correlation was found between the ability of phenolic extracts in chelating ferrous ions and the inhibition of LDL-c oxidation $(r=0.802$, $p>0.05$ ). In contrast, a significant correlation existed when the TPC was considered $(r=0.943, p<0.05)$. Compounds that do not bear catechol and/or galloyl groups in their structure do not show any complex formation (Andjelković et al., 2006). Syringic acid, which was present in five out of six samples, does not bear the mentioned moieties, which may help to explain the lack of correlation between the chelation capacity and the effect against LDL-c oxidation. However, it is important to mention that the inhibitory activity of soluble phenolics from four out of six wood extracts (SPW, OPW, OW, QW), was higher than $80 \%$. These results were statistically similar to those obtained for tannic and syringic acids (at $100 \mathrm{ppm}$ ), which along with gallic acid and catechin, were used as positive controls. In addition, tannic acid (inhibition of $88.0 \%$ ) and syringic acid (inhibition of $89.8 \%$ ) showed higher inhibitory activity than gallic acid $(72.4 \%)$ which was followed by catechin $(55.8 \%)$ thus supporting the differences found in different starting materials that may have a different phenolic profile. Finally, most soluble phenolic extracts obtained in the present study showed a higher inhibition activity against LDL-c oxidation compared to those released from the insoluble-bound form (data not shown), thus being the best fraction for potential development of nutraceuticals and/or pharmaceutical agents to prevent and/or decrease the risk of coronary heart diseases.

\section{Conclusions}

Irrespective of the wood sample, the fraction containing soluble phenolics was the most promising in terms of bioactive compounds. Several phenolic acids and flavonoids were identified by MALDI-TOF-MS. A positive correlation existed between TPC and reducing power. Likewise, the metal chelation capacity significantly correlated with TPC. Syringic acid, $(+)$-catechin, and $(+)$-gallocatechin were present in most samples and may be the responsible for the great ability of wood extracts in counteracting DNA damage and LDL-cholesterol oxidation. Wood phenolics may deserve further investigation in cardiovascular diseases, cancer prevention and/or treatment.

\section{Acknowledgments}

FS thanks the Natural Sciences and Engineering Research Council (NSERC) of Canada for partial financial support. One of us (TA) thanks the Umm AL-Qura University in Saudi Arabia. TA also acknowledges Saudi Cultural Bureau for her graduate scholarship.

\section{References}

Albishi, T., Banoub, J.H., de Camargo, A.C., and Shahidi, F. (2019a). Date palm wood as a new source of phenolic antioxidants and in preparation of smoked salmon. J. Food Biochem. 43: e12760.

Albishi, T., John, J.A., Al-Khalifa, A.S., and Shahidi, F. (2013a). Antioxidant, anti-inflammatory and DNA scission inhibitory activities of phenolic compounds in selected onion and potato varieties. J. Funct. Foods 5: 930-939.

Albishi, T., John, J.A., Al-Khalifa, A.S., and Shahidi, F. (2013b). Phenolic content and antioxidant activities of selected potato varieties and their processing by-products. J.Funct. Foods 5: 590-600.

Albishi, T., Mikhael, A., Shahidi, F., Fridgen, T.D., Delmas, M., and Banoub, J. (2019b). Top-down lignomic matrix-assisted laser desorption/ ionization time-of-flight tandem mass spectrometry analysis of lignin oligomers extracted from date palm wood. Rapid Commun. Mass Spectrom. 33: 539-560.

Alvarez-Parrilla, E., Urrea-López, R., and de la Rosa, L.A. (2018). Bioactive components and health effects of pecan nuts and their byproducts: a review. J. Food Bioact. 1: 56-92.

Amarowicz, R., and Shahidi, F. (2018). Antioxidant activity of faba bean extract and fractions thereof. J. Food Bioact. 2: 112-118.

Ambigaipalan, P., de Camargo, A.C., and Shahidi, F. (2016). Phenolic compounds of pomegranate byproducts (outer skin, mesocarp, divider membrane) and their antioxidant activities. J. Agric. Food Chem. 64: 6584-6604.

Andjelković, M., Van Camp, J., De Meulenaer, B., Depaemelaere, G., Socaciu, C., Verloo, M., and Verhe, R. (2006). Iron-chelation properties of phenolic acids bearing catechol and galloyl groups. Food Chem. 98: 23-31.

Crestini, C., Melone, F., Sette, M., and Saladino, R. (2011). Milled wood lignin: A linear oligomer. Biomacromolecules 12: 3928-3935.

de Camargo, A.C., Regitano-d'Arce, M.A.B., Biasoto, A.C.T., and Shahidi, F. (2016). Enzyme-assisted extraction of phenolics from winemaking by-products: antioxidant potential and inhibition of alpha-glucosidase and lipase activities. Food Chem. 212: 395-402.

de Camargo, A.C., Regitano-d'Arce, M.A.B., Gallo, C.R., and Shahidi, F. (2015). Gamma-irradiation induced changes in microbiological status, phenolic profile and antioxidant activity of peanut skin. J. Funct. Foods 12: 129-143.

de Camargo, A.C., Biasoto, A.C.T., Schwember, A.R., Granato, D., Rasera, G.B., Franchin, M., Rosalen, P.L., Alencar, S.M., and Shahidi, F. (2019). Should we ban total phenolics and antioxidant screening methods? The link between antioxidant potential and activation of NF-KB using phenolic compounds from grape by-products. Food Chem. 290: 229-238.

de Camargo, A.C., Schwember, A.R., Parada, R., Garcia, S., Maróstica, M.R., Franchin, M., Regitano-d'Arce, M.A.B., and Shahidi, F. (2018). Opinion on the hurdles and potential health benefits in value-added use of plant food processing by-products as sources of phenolic compounds. Int. J. Mol. Sci. 19: 3498.

Domenek, S., Louaifi, A., Guinault, A., and Baumberger, S. (2013). Potential of lignins as antioxidant additive in active biodegradable packaging materials. J. Polym. Environ. 21: 692-701.

Dudonné, S., Vitrac, X., Coutière, P., Woillez, M., and Mérillon, J.-M. (2009). Comparative study of antioxidant properties and total phenolic content of 30 plant extracts of industrial interest using DPPH, ABTS, FRAP, SOD, and ORAC assays. J. Agric. Food Chem. 57: 1768-1774.

Falcão, H.G., Silva, M.B.R., de Camargo, A.C., Shahidi, F., Franchin, M., Rosalen, P.L., Alencar, S.M., Kurozawa, L.E., and Ida, E.I. (2019). Optimizing the potential bioactivity of isoflavones from soybeans via ultrasound pretreatment: Antioxidant potential and NF-KB activation. J. Food Biochem. 43: e13018.

John, J., and Shahidi, F. (2019). Phenolic content, antioxidant and antiinflammatory activities of seeds and leaves of date palm (Phoenix dactylifera L.). J. Food Bioact. 5: 120-130.

Li, S., Gosslau, A., Lange, K., and Ho, C.-T. (2019). Profiled tea extracts exemplifying the importance of characterizing food bioactives: opinion piece. J. Food Bioact. 5: 1-5.

Liyana-Pathirana, C.M., and Shahidi, F. (2006). Importance of insolublebound phenolics to antioxidant properties of wheat. J. Agric. Food Chem. 54: 1256-1264.

Louli, V., Ragoussis, N., and Magoulas, K. (2004). Recovery of phenolic antioxidants from wine industry by-products. Bioresour. Technol. 92: 201-208.

Mirfat, A.H.S., Amin, I., Kartinee, K.N., Muhajir, H., and Shukri, M.A.M. (2018). Underutilised fruits: a review of phytochemistry and biologi- 
cal properties. J. Food Bioact. 1: 2-30.

Moure, A., Cruz, J.M., Franco, D., Domínguez, J.M., Sineiro, J., Domínguez, H., José Núñez, M.A., and Parajó, J.C. (2001). Natural antioxidants from residual sources. Food Chem. 72: 145-171.

Sathya, A., and Siddhuraju, P. (2012). Role of phenolics as antioxidants, biomolecule protectors and as anti-diabetic factors - Evaluation on bark and empty pods of Acacia auriculiformis. Asian Pac. J. Trop. Biomed. 5: 757-765.

Senanayake, N.S.P.J. (2018). Rosemary extract as a natural source of bioactive compounds. J. Food Bioact. 2: 51-57.

Shahidi, F., and Hossain, A. (2018). Bioactives in spices, and spice oleoresins: Phytochemicals and their beneficial effects in food preservation and health promotion. J. Food Bioact. 3: 8-75.

Shahidi, F., and Yeo, J. (2016). Insoluble-bound phenolics in food. Molecules 21: 1-22.
Shahidi, F., Varatharajan, V., Oh, W.Y., and Peng, H. (2019). Phenolic compounds in agri-food by-products, their bioavailability and health effects. J. Food Bioact. 5: 57-119.

Silva, C.P., Sampaio, G.R., Freitas, R.A.M.S., and Torres, E.A.F.S. (2018) Polyphenols from guaraná after in vitro digestion: Evaluation of bioacessibility and inhibition of activity of carbohydrate-hydrolyzing enzymes. Food Chem 267: 405-409.

Silva, C.P., Soares-Freitas, R.A.M., Sampaio, G.R., de Camargo, A.C., and Torres, E.A.F.S. (2019). Guarana as a source of bioactive compounds. J. Food Bioact. 6: 1-5.

Sosulski, F., Krygier, K., and Hogge, L. (1982). Free, esterified, and insoluble-bound phenolic acids. 3. Composition of phenolic acids in cereal and potato flours. J. Agric. Food Chem. 30: 337-340.

Valdez, J.C., and Bolling, B.W. (2019). Anthocyanins and intestinal barrier function: a review. J. Food Bioact. 5: 18-30. 